\title{
Redes Socio-ambientales en tensión: El caso de la gestión ambiental de los humedales de Bogotá.
}

\author{
Dolly Palacio ${ }^{1}$, Universidad Externado de Colombia, Rafael Hurtado², \\ Universidad Nacional de Colombia, Leonardo Garavito ${ }^{3}$, Universidad \\ Externado de Colombia
}

\begin{abstract}
Resumen
Los humedales de Bogotá se han convertido en el centro de una controversia entre la ciudadanía organizada y las entidades públicas locales responsables de su gestión ambiental, presentándose tensiones entre ellos, marcadas principalmente por criterios de uso urbanos y ambientales contrapuestos. Este artículo explora el carácter de estas tensiones en el marco del análisis de las relaciones de poder en dos direcciones: por un lado se estudian los aspectos estructurales de las interacciones socioambientales entre las organizaciones ciudadanas y con su entorno institucional y social alrededor de los humedales de Bogotá, entre 1999 y 2002, mediante la aplicación del Análisis de Redes Sociales. Del otro se identifican los discursos de los actores con relación a su acción en los humedales y el rol de algunos actores centrales, mediante la sociología de la traducción, mostrando que la estructura de relaciones entre los actores presenta tensiones que generan conflictos. Con este ejercicio se busca indagar sobre el surgimiento de las capacidades locales de las organizaciones ciudadanas para la gestión ambiental y la protección de los relictos de ecosistemas que co-existen con la ciudad, así como sobre las de movilizar a la ciudadanía para actuar dentro de la institucionalidad con el fin de reversar la tendencia actual de urbanización de los humedales. Esta última afecta tanto a los humedales en su función hídrica sobre la cuenca del rió Bogotá como la biodiversidad que alberga en sus hábitat. Se encuentra que las metodologías de análisis de las narrativas del Actor-Red y el Análisis de Redes Sociales pueden complementarse, facilitando el entendimiento de los procesos de configuración de los patrones de relaciones socio-ambientales y permitiendo evidenciar las tensiones y conflictos de uso del territorio. Adicionalmente, los resultados de esta aplicación contribuyen al diseño de políticas de participación en la gestión de la conservación de estos ecosistemas estratégicos.
\end{abstract}

\footnotetext{
${ }^{1}$ Dolly Cristina Palacio: dolly.palacio@uexternado.edu.co

${ }^{2}$ Rafael Hurtado: rhurtado@ocyt.org.co

${ }^{3}$ Leonardo Garavito: luis.garavito@uexternado.edu.co
} 


\section{Introducción}

La gestión ambiental es un ejercicio complejo que involucra tanto el entendimiento de las relaciones de los seres humanos y no-humanos con su entorno, como la acción que se debe realizar sobre éstas para lograr mantener un estado ambiental deseado. La gestión ambiental, entendida como un proceso de ordenamiento, puede llevarse a cabo de dos modos (Lee y Stainer, 1999). El primero es del tipo que privilegia un determinado orden excluyendo otros, donde un deber ser establecido a priori impone qué se ordena, cómo se ordena y para qué se ordena. El segundo es del tipo que ensambla las distintas lógicas de orden, donde los actores interactúan entre si y con su entorno creando vínculos entre ellos que, aunque los actores se diferencien en sus lógicas de aproximación, buscan establecer dinámicas colectivas incrementando así el poder de todos aquellos que se articulan al proceso (Hanneman 2001). Este último modo implica identificar y reconocer las características de los actores y sus relaciones con el entorno, para así identificar las tensiones entre ellos y proponer caminos políticos de resolución de las mismas.

La gestión de las Áreas Protegidas ${ }^{4}$ (AP) se ha desarrollado tradicionalmente con base en un 'modelo normativo' de la gestión, es decir mediante procesos que pretenden ordenar las acciones humanas y su entorno mediante mecanismos jurídicos que, en muchos casos, adquieren su legitimidad del conocimiento científico ${ }^{5}$ (Latour en Boczkowski, 1997). Durante la última década la gestión de la conservación en las AP busca encontrar un orden deseado mediante la participación de actores heterogéneos, en la que 'el consenso' es la base sobre la cual se legitima dicho orden (West y Brechin, 1991; Ghimire y Pimbert, 1997). Actualmente se puede decir que en la noción de 'orden', implícita en los asuntos de la gestión de la conservación de las AP, se encuentran tres formas de legitimidad, superpuestas: la jurídica (normas), la científica (teorías) y la política (acuerdos). Estas tres formas de legitimación constituyen el marco para el debate entre los actores vinculados a las AP por sus prácticas y discursos.

El objetivo central de este artículo es mostrar un camino metodológico para reconocer las tensiones sociales existentes en las relaciones socio-ambientales de las AP, mediante el caso de la gestión ambiental de los humedales de Bogotá por parte de las organizaciones

\footnotetext{
${ }^{4}$ Areas Protegidas 'son segmentos de tierra o mar destinados para la conservación de la biodiversidad y de los procesos culturales asociados con el mantenimiento de los recursos naturales mediante disposiciones legales y otros medios efectivos' (McNeely, 1994).

${ }^{5}$ El conocimiento científico al que se refiere el autor es aquel que 'apela a los seres nohumanos para que sean inhumanos, es decir normaliza con leyes impersonales para interrumpir el debate político' (Latour, 1997:148).
} 
ciudadanas de la Red de Humedales de la Sabana de de Bogotá, $\mathrm{RHSB}^{6}$. En este artículo los humedales de Bogotá, definidos desde los acuerdos municipales como $\mathrm{AP}^{7}$, se analizan como el resultado de la gestión ambiental de organizaciones ciudadanas vinculadas misionalmente con su conservación y de los actores del entorno institucional y social, incluyendo al Estado y diversas organizaciones privadas que están a su vez vinculados a la acción de las primeras. Debido a que los humedales no han sido definidos de una forma homogénea por los actores involucrados en su gestión ambiental, surgen tensiones y conflictos que juegan un papel determinante en el logro de los propósitos de cada uno de ellos. Por lo tanto, el conocimiento de la heterogeneidad de las prácticas y los significados que los distintos actores dan a la gestión ambiental de las AP es de gran importancia para generar procesos políticos y de investigación, que permitan una gestión que ensamble las distintas lógicas de orden.

El artículo se divide en tres partes: la primera hace una presentación de la noción del Lugar-Red, como una perspectiva teórica que explica las relaciones socio-ambientales en el marco de las relaciones de poder (Palacio 2001, 2002) y las metodologías del Análisis de Redes Sociales (ARS) y las narrativas del Actor-Red como formas de aproximarse al conocimiento del Lugar-Red. La segunda es una aplicación de las herramientas analíticas del ARS (Freeman, 1979, 2002; Wasserman y Faust, 1994; Diani, 1995; Faust, 2002; Borgatti, 2003) al caso de la gestión ambiental de los humedales de Bogotá por parte de la RHSB, utilizando medidas de centralidad y cohesión de subgrupos para identificar los actores más prominentes de la RHSB y el entrono institucional y social con el que aquellas se desempeñan. En la tercera se aplica la sociología de la traducción, mediante las narrativas del Actor-Red (Callon, 1986 y Law, 1992, 1996), seleccionando del mismo caso algunos de los actores más prominentes identificados con el ARS, evidenciando tensiones entre éstos mediante sus discursos y prácticas de gestión ambiental en los humedales de Bogotá.

${ }^{6}$ La RHSB es una alianza establecida en 1999 entre un conjunto de organizaciones ciudadanas con intereses directos en la conservación de los humedales de Bogotá como ecosistemas relictuales en el marco del desarrollo urbano de Bogotá. Sus reuniones presenciales son mensuales y sus estrategias de comunicación son el boletín Entre Juncos y el intercambio por correo electrónico.

7 El Acuerdo 6 de 1990, el acuerdo 19 del 1994 y el acuerdo 27 de 1995 designan los humedales de Bogotá como Áreas Protegidas y Reservas Naturales. 


\section{El Lugar-Red como unidad de Análisis}

En el marco de la gestión de las AP el análisis de lugar cobra relevancia por la forma en la cual los espacios geográficos son definidos por los actores y ésta influye sobre la configuración del paisaje en lugares específicos (Ghimire y Pimbert, 1997; West y Brechin, 1991). El lugar como concepto es un elemento complejo cuyo entendimiento requiere de abordar tanto los aspectos objetivos como los subjetivos de la configuración del espacio, así como los arreglos socioambientales en un locus ${ }^{8}$ geográfico.

La noción de el Lugar-Red (Palacio, 2001, 2002) busca como concepto compuesto definir El lugar, como una consecuencia de una multiplicidad de discursos, subjetividades, interacciones y relaciones de poder que se desarrollan en el tiempo y el espacio, y La red, como un patrón de vínculos específicos entre un conjunto determinado de actores, donde cualquier variación en la existencia o en el nivel de fortaleza de un vínculo es significativo y tiene consecuencias sobre el todo. La red está configurada por los nodos o actores y sus vínculos con otros actores o con entidades no humanas a las que el actor se afilia (individual o colectivamente) mediante su práctica para llevar a cabo sus propósitos. El Lugar-Red, como unidad de análisis, busca conocer sobre las interacciones socio-ambientales haciendo hincapié en cuatro componentes de esta interacción: el actor social, el espacio y el tiempo, el ambiente y el poder.

El actor social es el sujeto que ejerce la acción, es el polo de la agencia en el campo de la interacción (Law, 1999; Latour, 1999). El actor puede ser un individuo o una organización cuyos propósitos o intereses específicos se resuelven mediante la interacción social. El actor es una unidad social relacional. Se es actor en tanto se tiene una posición en un esquema relacional, es decir que el actor es una unidad interdependiente, cuyos vínculos con otros actores y sus afiliaciones son parte de su configuración como tal. Los vínculos entre los actores pueden ser directos o indirectos. Directos cuando los actores están relacionados por una interacción explicita y hay interdependencia; indirectos cuando los actores están compartiendo una actividad o recurso común (Diani, 2003:7). La dimensión espacio-temporal es el marco básico en el cual se inscriben la práctica y los significados de los actores sociales. El espacio y el tiempo funcionan como límites y potencialidades de la acción, pues con ellos es posible identificar la duración y la localización de la acción. La construcción de los lugares se da en un diálogo permanente, en la que el tiempo y el espacio son elementos consustanciales a las interacciones humanas (Thrift,1996). EI ambiente está compuesto por todas aquellas entidades no

\footnotetext{
8 locus significa local, califica a algo o alguien que pertenece o está adscrito a un sitio geográfico específico. También denota el espacio creado por la interacción social en el tiempo y el espacio.
} 
humanas que pueden ser entendidas desde su doble naturaleza de ser a la vez objetivas y subjetivas (Inglod,1992). Su existencia objetiva se refleja en 'las cosas' como entidades independientes de los actores sociales y su percepción sobre ellas. Su construcción subjetiva se refleja en la apropiación que los actores sociales hacen del ambiente en su práctica social específica, donde los elementos que lo componen adquieren un significado particular (Ingold, 1992). EI poder es entendido como un efecto de las dinámicas colectivas y como efecto relacional implica patrones de orden y participación. El poder se identifica aquí con el logro o alcance de los objetivos y el mantenimiento de los logros por parte de determinados patrones de relación (Clegg, 1989).

\subsection{El Análisis de Redes Sociales}

Una de las principales herramientas metodológicas para representar El Lugar-Red, y en particular las interacciones socio-ambientales que hacen parte de él, es el ARS. Este tipo de análisis permite develar elementos estructurales según distintos aspectos sociales, ambientales y económicos entre otros (Wasserman y Faust, 1994; Diani, 1995, 2003 Faust, 2002; Ansell, 2003). En el caso de la gestión ambiental de los humedales de Bogotá, la herramienta del Lugar-Red permite identificar patrones y prominencias en las relaciones sociales y socioambientales en estas áreas geográficas definidas como AP. Así mismo, contribuye a la comprensión de las estructuras de poder de los actores involucrados en la gestión ambiental, teniendo en cuenta que esta perspectiva enfatiza que el poder es inherentemente relacional (Hanneman, 2001).

Para el caso de la gestión de los humedales de Bogotá se estudiaron 8 humedales identificados en el Plan de Ordenamiento de la Ciudad, Tabla 1., y tres tipos de vínculos: las interacciones explícitas entre las organizaciones ciudadanas de la RHSB, establecidas mediante las actividades llevadas a cabo conjuntamente en cada humedal (Ej.: reforestación, limpiezas, observaciones de campo, educación ambiental, demandas jurídicas, entre otras), consideradas como vínculos directos entre actores de la RHSB; las interacciones explícitas entre las organizaciones ciudadanas de la RHSB y el entrono institucional y social (ej: reuniones, jornadas de trabajo en el humedal, demandas jurídicas, apoyo financiero, acuerdos y disputas en escenarios de toma de decisiones), consideradas como vínculos directos de la RHSB y el entorno institucional y social. A partir de los patrones de relación entre las organizaciones ciudadanas de la RHSB con los actores del entorno institucional y social se encuentra un tercer vínculo entre ellos, en este caso indirecto y mediado por el entorno. 


\begin{tabular}{|l|l|}
\hline NODOS DE LA RED DE HUMEDALES & \multicolumn{1}{c|}{ HUMEDALES } \\
\hline Fundación Humedal La Conejera & H. La Conejera \\
\hline Fundación humedales El Tintal & H. Tintal (3 humedales integrados) \\
\hline Fundación humedal Torca-Guaymaral & H. Torca - Guaymaral \\
\hline Fundación La Tingua & H. Santa María del Lago \\
\hline & \\
\hline AUNAR & H. Tibanica \\
\hline Junta de Acción Comunal de Niza & H. Córdoba \\
\hline Asoc. Para el DEsarrollo Social y Amb. & H. Jaboque \\
\hline Cabildo Verde de Soacha & H. Neuta \\
\hline
\end{tabular}

Tabla 1: Nodos de la RHSB y los humedales. El bloque superior corresponde a las cuatro fundaciones cuya única misión es la de conservar los humedales, las del bloque inferior son organizaciones ciudadanas que tienen misiones dirigidas a la comunidad $y$ que involucran temáticas ambientales en torno a los humedales en su agenda.

En este trabajo se realizan análisis de centralidad -grado, cercanía e intermediación- y de cohesión de subgrupos (Freeman 1979, Wasserman y Faust, 1994; Hanneman, 2001), con el fin de evidenciar algunos elementos estructurales asociados a aspectos relacionales, tanto endógenos como exógenos de la RHSB. Para el procesamiento de los datos se utilizó UCINET VI (Borgatti, Everett y Freeman, 2002).

\subsection{Aspectos metodológicos para la construcción de las narrativas}

Los humedales de Bogotá, entendidos como Lugares-Red, son estudiados desde las narrativas de los actores relacionados con su gestión ambiental, mediante la identificación de sus discursos y prácticas sobre los humedales, evidenciando las tensiones entre ellos. Para construir este mapa cualitativo de los actores es necesario conocer, además de los discursos de cada actor, cómo estos discursos están organizados en el plano de las relaciones de poder.

La construcción de las narrativas en el plano de las relaciones de poder se hace aplicando el esquema de la sociología de la traducción (Callon,1986; Clegg 1989; Thrift, 1996). La traducción es una estrategia narrativa que da cuenta de los acuerdos, controversias, disidencias y traiciones que se dan en los procesos de apropiación de los recursos materiales y simbólicos por parte de los actores sociales para alcanzar unos propósitos determinados. El poder aquí está relacionado con el alcance de objetivos, es decir con el logro. El poder es entonces en este contexto un efecto y no una causa de la acción. Quien logra lo que se propone se puede decir que ha conseguido con éxito la traducción de su entorno en pos de un objetivo.

La traducción tiene cuatro movimientos: (i) la problematización, mediante la cual los actores definen un problema o un asunto cualquiera de la realidad sobre la que actúan identificándose a sí mismos como actores indispensables para resolver dicho problema o actuar sobre dicho asunto, constituyéndose en nodos de paso obligado. Los nodos de paso obligado son aquellos actores que se definen a sí 
mismos como 'el interesado central' frente a 'un asunto' y por lo tanto es quien dice cómo se actúa y con quién se actúa sobre el mismo (Callon,1986). Este concepto es muy importante para describir las tensiones entre los actores frente a un asunto determinado, es decir, denota quién es el actor central en la red, quién sostiene los vínculos y es efectivo en su agencia; (ii) Interesar o el proceso mediante el cual los actores buscan comprometer a otros sobre su problema para actuar como aliados suyos; (iii) El reclutamiento o enrolamiento mediante el cual los actores buscan involucrar a otros en su acción asignándoles roles específicos; (iv) Finalmente, la movilización o proceso mediante el cual los actores buscan lograr sus propósitos a pesar de que muchas veces no lo consiguen.

\section{El Lugar-Red y la gestión ambiental de los humedales de Bogotá: elementos estructurales prominentes}

En esta sección se presentan los distintos elementos estructurales de la RHSB, partiendo de consideraciones relacionales entre los actores involucrados en la gestión de los humedales de Bogotá. Para esto se estudian tres escenarios: el primero de ellos corresponde a la observación de los vínculos directos entre las organizaciones ciudadanas de la RHSB, tal como se definieron arriba. En el segundo se ponderan los vínculos entre las organizaciones de la RHSB en cuanto a su interacción con el entorno institucional y social. En el tercero se aborda la emergencia de una estructura en el entorno institucional y social, proveniente de que sus actores, a su vez, interactúan con las organizaciones de la RHSB.

\subsection{Los vínculos directos entre las organizaciones de la RHSB}

El primer vínculo estudiado es la interacción explicita (Diani, 2003) entre las organizaciones de la RHSB, Tabla 1, definida por la realización conjunta de actividades para la gestión de cada humedal. Estas actividades apoyan a cada nodo en el logro de sus objetivos y, en este sentido, la existencia de esta interacción beneficia a los participantes mediante el intercambio de conocimiento, competencias, posibilidades de relacionarse y capacidad ejecutora. Ejemplos de esta relación son los procesos de demarcación de linderos, arborización, limpieza, educación y litigio y concertación con las autoridades, comunidades y todos los interesados. Algunos de los beneficios directos que reciben las organizaciones es el mejoramiento del conocimiento que tienen sobre su entorno, sobre si mismas y sobre sus relaciones, así como el mejoramiento de sus prácticas en cuanto a traducción, planeación, negociación y ejecución.

En la Tabla 2 se pueden observar las interacciones que cada una de las organizaciones de la RHSB establece con otra. Las organizaciones se denominan por el nombre del humedal al cual están vinculadas. 


\begin{tabular}{|l|l|c|c|c|c|c|c|c|c|}
\hline & Socio-matriz & $\mathbf{1}$ & $\mathbf{2}$ & $\mathbf{3}$ & $\mathbf{4}$ & $\mathbf{5}$ & $\mathbf{6}$ & $\mathbf{7}$ & $\mathbf{8}$ \\
\hline $\mathbf{1}$ & Conejera & 0 & 1 & 1 & 1 & 1 & 1 & 1 & 1 \\
\hline $\mathbf{2}$ & Córdoba & 1 & 0 & 1 & 1 & 1 & 1 & 1 & 1 \\
\hline $\mathbf{3}$ & Tibanica & 1 & 1 & 0 & 1 & 0 & 1 & 0 & 0 \\
\hline $\mathbf{4}$ & Jaboque & 1 & 1 & 1 & 0 & 0 & 1 & 1 & 1 \\
\hline $\mathbf{5}$ & Torca-Guyamaral & 1 & 1 & 0 & 0 & 0 & 0 & 0 & 0 \\
\hline $\mathbf{6}$ & Tintal & 1 & 1 & 0 & 0 & 1 & 0 & 1 & 0 \\
\hline $\mathbf{7}$ & Santa Ma. del Lago & 1 & 1 & 1 & 1 & 1 & 0 & 0 & 0 \\
\hline $\mathbf{8}$ & Neuta & 1 & 1 & 0 & 0 & 0 & 1 & 0 & 0 \\
\hline
\end{tabular}

Tabla 2: Vínculos directos entre organizaciones ciudadanas de la RHSB por interacción explícita: identificación de actividades llevadas a cabo conjuntamente en beneficio de cada humedal.

Una primera medida aplicada a esta red es la de cohesión, una de sus propiedades globales, según la cual la red tiene el $60 \%$ del total de los vínculos posibles.

\subsubsection{Análisis de centralidad}

La primera medida de centralidad se tomó con base en el grado nodal de Freeman, definido como el total de vínculos que tiene cada actor en la red. Aplicando este indicador de centralidad se encuentra en la Tabla 3 que la Conejera y Córdoba se vinculan con todas las demás organizaciones de la RHSB, y por lo tanto son los actores más prominentes de la red, seguidos por Tintal, Jaboque, y Santa. Ma. del Lago. La asimetría de la matriz refleja las diferencias entre los humedales que han sido beneficiados con las actividades que se desarrollaron conjuntamente, y se evidencia en los resultados de los grados de salida y de entrada de la matriz, que podrían eventualmente asociarse al posicionamiento de los actores dentro de la red en cuanto a prestigio y expansividad (Wasserman y Faust, 1994; Faust, 2002). Esta asimetría puede provenir de múltiples situaciones como distintas dinámicas o capacidades de las organizaciones de la RHSB, la relación entre dinámica interna y dinámica externa, percepción, definición del intercambio entre otras. Se trata de una asimetría pequeña, principalmente entre Jaboque y Torca-Guaymaral.

La centralización de la red, definida como la suma de las diferencias entre la centralidad máxima y la de cada uno de los actores, y ajustando la máxima centralidad al $100 \%$, es de $36.7 \%$ para los grados de entrada y de salida. 


\begin{tabular}{|l|c|c|c|c|c|c|c|}
\hline & $\begin{array}{c}\text { Grado de } \\
\text { Salida }\end{array}$ & $\begin{array}{c}\text { Grado de } \\
\text { Entrada }\end{array}$ & $\begin{array}{c}\text { Distancia } \\
\text { Exterior }\end{array}$ & $\begin{array}{c}\text { Distancia } \\
\text { Interior }\end{array}$ & $\begin{array}{c}\text { Cercanía } \\
\text { Exterior }\end{array}$ & $\begin{array}{c}\text { Cercanía } \\
\text { Interior }\end{array}$ & $\begin{array}{c}\text { Interme } \\
\text { diación }\end{array}$ \\
\hline Conejera & 7 & 7 & 7 & 7 & $100 \%$ & $100 \%$ & 7 \\
\hline Córdoba & 7 & 7 & 7 & 7 & $100 \%$ & $100 \%$ & 7 \\
\hline Tibanica & 4 & 4 & 10 & 10 & $70 \%$ & $70 \%$ & 0 \\
\hline Jaboque & 6 & 4 & 10 & 8 & $70 \%$ & $88 \%$ & 1 \\
\hline Torca-Guyamaral & 2 & 4 & 10 & 12 & $70 \%$ & $58 \%$ & 0 \\
\hline Tintal & 4 & 5 & 9 & 10 & $78 \%$ & $70 \%$ & 2 \\
\hline Santa Ma. del Lago & 5 & 4 & 10 & 9 & $70 \%$ & $78 \%$ & 1 \\
\hline Neuta & 3 & 3 & 11 & 11 & $64 \%$ & $64 \%$ & 0 \\
\hline
\end{tabular}

Tabla 3: Medidas de centralidad clásicas para la red de las organizaciones ciudadanas de la RHSB vinculadas directamente.

La segunda medida de centralidad aplicada es el grado de cercanía (Freeman 1979, 2002) que define la distancia geodésica entre dos nodos de la red como la longitud del camino más corto entre ellos. La centralidad de cercanía de un nodo es definida como el inverso de la suma de las distancias geodésicas del nodo a todos los demás Tabla 3. En este caso cada segmento mide 1 y la centralización de la red es del $55.3 \%$ en el grado de salida y de $53.5 \%$. en el de entrada.

La tercera medida de centralidad es el grado de intermediación de Freeman, definido para un nodo como el máximo número de caminos geodésicos que pasan por él y que unen otros dos nodos. En este caso no se considera la direccionalidad de los vínculos en la red. Tabla 3.

Los tres análisis arrojan resultados consistentes entre sí, con distinto nivel de sensibilidad. De una parte se reconocen las organizaciones de la Conejera y Córdoba como las más centrales en todas las situaciones, lo que permite concluir que como actores más expansivos, prestigiosos, cercanos y mediadores del conjunto, marcan una prominencia importante en la red (ver figura 1). De éste y los anteriores análisis se evidencia que la organización ciudadana vinculada a la gestión de los humedales del Tintal juega un papel intermedio dentro de la RHSB. 


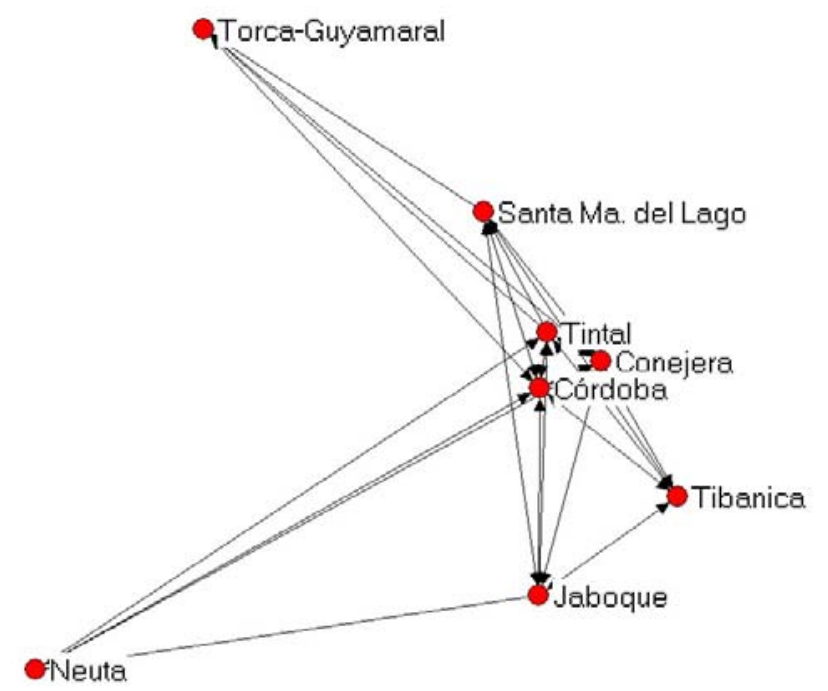

Figura1: Representación de la red de acuerdo a la cercanía de sus nodos. (Draw, Borgatti, 2002)

La prominencia de la Conejera y Córdoba en la red refleja sus capacidades de intercambio y apoyo, de difusión y de centralización del tema de la gestión ambiental. Estas medidas los destacan como líderes de la gestión en el marco de la RHSB, al mismo tiempo que surgen preguntas sobre el papel de la centralidad en las relaciones de poder. El poder si bien es un efecto, reflejado en la capacidad de los actores para lograr sus propósitos, también se puede interpretar como una capacidad de influencia de unos actores sobre un ámbito articulado estructuralmente, como la RHSB, presentando un isomorfismo en las misiones y visiones de sus miembros provocado por los actores más prominentes.

\subsubsection{Agrupación por cohesión.}

Con base en la aplicación del cliqué como criterio de medida de cohesión se identificaron 3 subgrupos en la red.

1: Conejera, Córdoba, Tintal, Tibanica, Jaboque y Santa Ma. Del Lago

2: Conejera, Córdoba, Tintal, Santa Ma. Del Lago, Torca-Guaymaral

3: Conejera, Córdoba, Tintal, Jaboque, Neuta

En este caso los nodos de la Conejera, Córdoba y Tintal pertenecen a los tres cliqués, Jaboque y Santa Ma. del Lago a dos y los demás a uno. Mientras que prevalece el papel central de las dos primeras, el nodo del Tintal se distingue claramente de las demás, mientras que los de Neuta y Torca-Guaymaral resultan relativamente periféricos. Figura 2. 


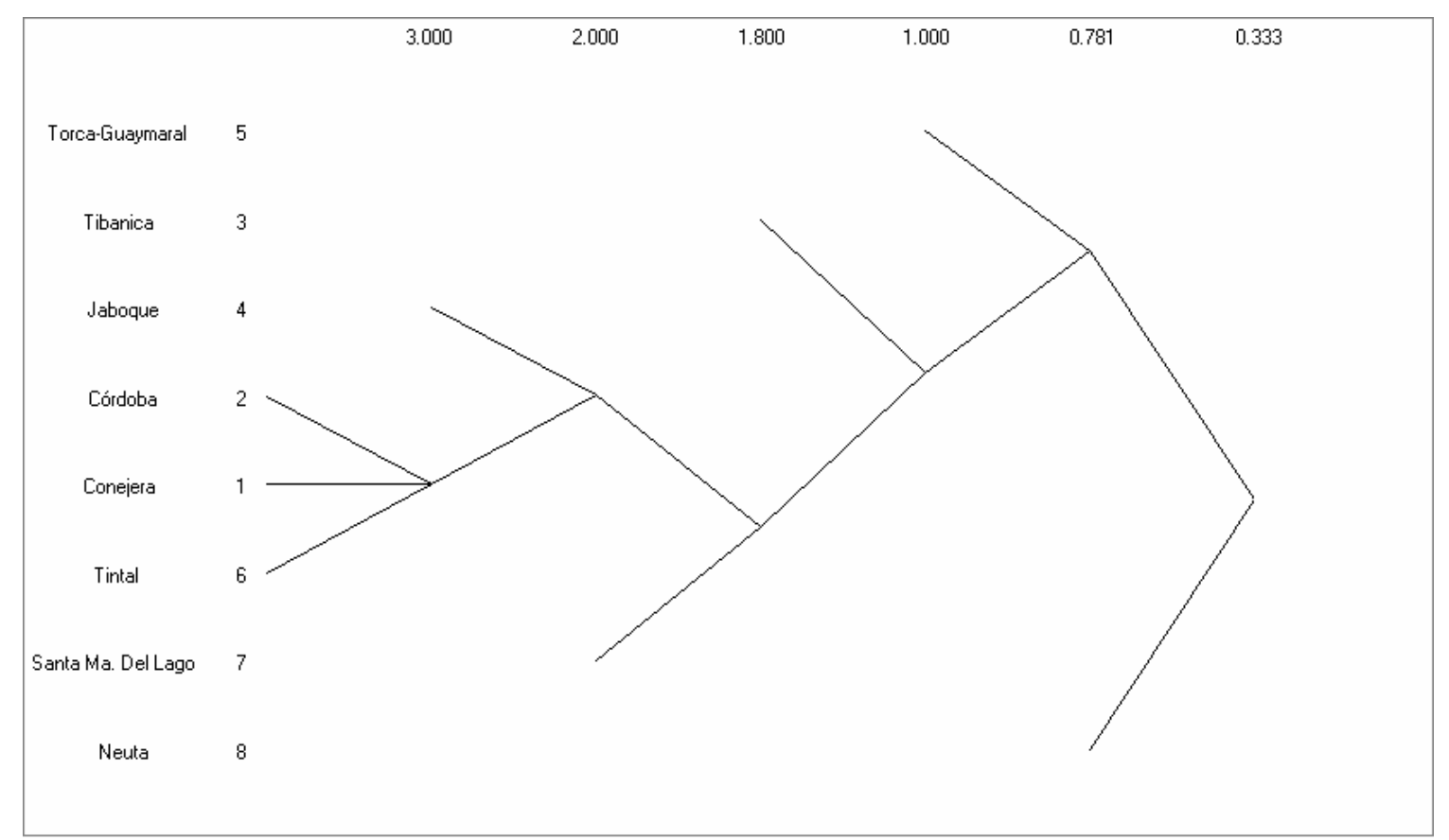

Figura 2: Presentación en la forma de árbol de los cliqués de la RHSB según sus vínculos directos. (Draw, Borgatti, 2002)

\subsection{Los vínculos indirectos entre las organizaciones de la RHBS}

El segundo vínculo estudiado es indirecto y se realiza a través del entorno institucional y social de la RHSB, con el que interactúan las organizaciones ciudadanas de la RHSB.

La interacción explícita de las organizaciones de la RHSB con actores de su entorno, a través de la ejecución, financiación o facilitación de acciones y proyectos entre otros, puede realizarse de manera individual o colectiva, tener naturaleza cooperativa o de oposición o competitiva y afectar positiva o negativamente el logro de objetivos comunes y no comunes. Este criterio se puede ver en el estudio de Ansell (2003) sobre el movimiento ambiental en la Bahía de San Francisco con respecto al problema de la gobernabilidad colaborativa y la 'encarnación'9 de las organizaciones en su propia subcultura.

La interacción explícita entre las organizaciones ciudadanas de la RHSB y los actores del entorno institucional y social puede transformar a los

${ }^{9}$ Embeddedness es un concepto que ha sido problemático para tratar en la lengua española, pero su acepción en ARS tiene que ver con los procesos de estructuración social que llevan a crear círculos de relación establecidos mediante por ejemplo el parentesco, la confianza y la amistad, que facilitan otro tipo de relaciones como las económicas y cuya 'red' se 'encarna' (incorpora) en la otra. 
distintos actores y/o alinearlos alrededor de una problemática o un criterio de acción. Estas transformaciones pueden ser individuales o colectivas, y darse en la dinámica o en la estructura, favoreciendo o no los logros de las organizaciones de la RHSB. En este contexto es posible definir un vínculo indirecto entre las organizaciones de la RHSB. Ejemplos de este tipo de vínculo son la generación de políticas y acciones institucionales que favorecen sus actividades, así como la competencia por recursos limitados.

El vínculo indirecto entre organizaciones ciudadanas de la RHSB se define en esta aplicación a partir de la existencia o no de interacciones explícitas simultáneas entre las organizaciones de la RHSB con actores del entorno institucional o social.

Esta definición del vínculo indirecto no considera la naturaleza, magnitud o alineación de la interacción explícita entre actores de la RHSB y del entorno institucional y social; tampoco distingue entre acciones individuales y colectivas. Adicionalmente se presentan relaciones ambivalentes entre pares de actores, en las cuales distintas acciones específicas pueden tener efectos opuestos sobre el logro de sus propósitos. Por lo tanto discernir elementos asociados a tensiones o conflictos de efectos colectivos o de coherencia, y en particular reconocer si la interacción entre los actores es competitiva (eventualmente excluyente) o cooperativa (fundamentalmente incluyente), demanda esfuerzos adicionales en el contexto del ARS.

\subsubsection{Actores del entorno institucional y social}

El entorno institucional y social con el cual interactúan las organizaciones ciudadanas de la RHSB es complejo y diverso. Los actores del entorno son variados en su naturaleza, misión y estructura interna, actuando con distintas estrategias y capacidades $y$, por lo tanto, con mayor o menor impacto y con mayor o menor capacidad de transformación propia y del entorno. Entre estos actores se encuentran entidades del Estado central, regional y local, organizaciones ciudadanas con y sin ánimo de lucro, poblaciones que por distintos motivos se relacionan con los humedales y otros actores con intereses que incluyen los económicos. Aquellos con los cuales las organizaciones de la RHSB manifiestan tener alguna relación en el contexto del cumplimiento de su misión figuran en la Tabla 4.

\begin{tabular}{|l|l|}
\hline \multicolumn{1}{|c|}{ SECTOR ESTADO } & \multicolumn{1}{c|}{ SECTORES CIVILES } \\
\hline Min. Medio Ambiente & RHSB \\
\hline Corporación Autónoma Regional & Comunidad Perimetral \\
\hline Alcaldía Mayor de Bogotá & Grupos Ecológicos Locales \\
\hline $\begin{array}{l}\text { Empresa de Acueducto y Alcantarillado de } \\
\text { Bogotá }\end{array}$ & Urbanizadores Locales \\
\hline
\end{tabular}




\begin{tabular}{|l|l|}
\hline Departamento Administrativo del M.A. & Fincas aledañas \\
\hline Organismos de Control del Estado & Colegios Vecinos \\
\hline Juzgados & Universidades \\
\hline Jardín Botánico de Bogotá & Asociación Bogotana de Ornitología \\
\hline La Policía Metropolitana & $\begin{array}{l}\text { Aseo total (servicio recolección de } \\
\text { basuras) }\end{array}$ \\
\hline Los Bomberos de Bogotá & Planeta Paz \\
\hline Alcaldías Locales & Red Paz \\
\hline Juntas de Acción Comunal & Fundepúblicos \\
\hline Comité técnico de Humedales de Bogotá & Ecofondo \\
\hline & Paz Verde \\
\hline & Comité Pro-árbol \\
\hline & City TV \\
\hline
\end{tabular}

Tabla 4: Entorno institucional y social en el que actúan las organizaciones ciudadanas de la RHSB.

\subsubsection{Los vínculos entre organizaciones de la RHSB mediados por el entorno institucional y social}

La matriz de la Tabla 5 se deriva de tomar los vínculos directos entre las organizaciones ciudadanas de la RHSB con actores de su entorno institucional y social. Se define el vínculo indirecto entre las organizaciones de la RHSB tomando la suma del número de actores del entorno con los cuales ellas interactúan simultáneamente. Matemáticamente se trata del producto de la matriz de afiliación (con entradas binarias) por su transpuesta. 


\begin{tabular}{|c|l|c|c|c|c|c|c|c|c|}
\hline & $\begin{array}{l}\text { Vínculo mediado } \\
\text { por el entorno }\end{array}$ & $\mathbf{1}$ & $\mathbf{2}$ & $\mathbf{3}$ & $\mathbf{4}$ & $\mathbf{5}$ & $\mathbf{6}$ & $\mathbf{7}$ & $\mathbf{8}$ \\
\hline $\mathbf{1}$ & Conejera & $\mathbf{2 2}$ & 13 & 8 & 5 & 6 & 8 & 5 & 6 \\
\hline $\mathbf{2}$ & Córdoba & 13 & $\mathbf{1 4}$ & 6 & 5 & 5 & 8 & 6 & 5 \\
\hline $\mathbf{3}$ & Tibanica & 8 & 6 & $\mathbf{1 0}$ & 5 & 3 & 5 & 4 & 2 \\
\hline $\mathbf{4}$ & Jaboque & 5 & 5 & 5 & $\mathbf{5}$ & 3 & 4 & 3 & 2 \\
\hline $\mathbf{5}$ & Torca-Guyamaral & 6 & 5 & 3 & 3 & $\mathbf{6}$ & 3 & 3 & 4 \\
\hline $\mathbf{6}$ & Tintal & 8 & 8 & 5 & 4 & 3 & $\mathbf{1 1}$ & 3 & 3 \\
\hline $\mathbf{7}$ & S. Ma. del Lago & 5 & 6 & 4 & 3 & 3 & 3 & $\mathbf{6}$ & 2 \\
\hline $\mathbf{8}$ & Neuta & 6 & 5 & 2 & 2 & 4 & 3 & 2 & $\mathbf{9}$ \\
\hline
\end{tabular}

Tabla 5: Vínculos indirectos entre organizaciones ciudadanas de la RHSB: provienen de la identificación de vínculos simultáneos entre actores de la RHSB y del entorno institucional y social.

Esta matriz es simétrica por construcción. Comparando esta matriz con la de vínculos directos se encuentra que, al dicotomizarla con un umbral de $5^{10}$, la coincidencia es del $86 \%$. Este resultado evidencia una fuerte correlación entre los vínculos directos e indirectos de la red.

\subsubsection{Análisis de centralidad}

Aplicando las medidas de centralidad de grado, cercanía e intermediación a esta matriz, se obtiene que los rasgos generales sobre la centralidad de los dos actores más prominentes en la red prevalecen, la Conejera y Córdoba. Ver Tabla 6. La principal variación con respecto al caso anterior es que Tibanica tiene el papel de mayor centralidad, mientras que Tintal de menor. Para hacer el análisis de intermediación se toma la matriz dicotomizada con un umbral de 4.98, correspondiente al promedio de las entradas fuera de la diagonal.

10 El umbral se toma considerando que el promedio para todas las interacciones es de 4.2 excluyendo la diagonal y de 5.5 incluyéndola. Adicionalmente el nodo con menor número de vínculos con actores del entrono tiene como entrada 5. 
Para la matriz dicotomizada la centralización de grado de la red es de $61.90 \%$ mientras que para la de cercanía es de $70.49 \%$.

\begin{tabular}{|l|c|c|c|c|}
\hline & Grado & Distancia & Cercanía & Intermediación \\
\hline Conejera & 73 & 7 & $100 \%$ & 6.3 \\
\hline Córdoba & 62 & 7 & $100 \%$ & 6.3 \\
\hline Tibanica & 43 & 10 & $70 \%$ & 0.3 \\
\hline Jaboque & 32 & 11 & $64 \%$ & 0 \\
\hline Torca-Guyamaral & 33 & 11 & $64 \%$ & 0 \\
\hline Tintal & 45 & 12 & $58 \%$ & 0 \\
\hline S Ma.del Lago & 32 & 12 & $58 \%$ & 0 \\
\hline Neuta & 33 & 12 & $58 \%$ & 0 \\
\hline
\end{tabular}

Tabla 6: Medidas de centralidad clásicas para la red de las organizaciones ciudadanas de la RHSB con vínculos indirectos.

\subsubsection{Agrupación por cohesión}

Los cliqués que se encuentran para esta matriz, dicotomizada de igual manera que para el análisis de centralidad de intermediación, son los siguientes:

1: Conejera, Córdoba, Tibanica, Jaboque

2: Conejera, Córdoba, Tibanica, Tintal

3: Conejera, Córdoba, Torca-Guaymaral

4: Conejera, Córdoba, Santa Ma. Del Lago

5: Conejera, Córdoba, Neuta

Nuevamente Córdoba y la Conejera son los más prominentes, mientras que Tibanica apenas se destaca de los demás. El mayor número de cliqués con respecto a la situación con vínculos directos, y el menor tamaño de estos, indica una menor relación entre los actores periféricos, consistentemente con un aumento en la centralización en la matriz de cercanía. 




Figura 4: Presentación en la forma de árbol de los cliqués de la RHSB según sus vínculos indirectos. (Draw, Borgatti, 2002)

\subsection{Los vínculos indirectos entre los actores del entorno institucional y social}

La segunda matriz que se deriva de los vínculos directos, interacción explícita, entre las organizaciones ciudadanas de la RHSB y los actores de su entorno institucional y social, se define como el número de organizaciones ciudadanas de la RHSB con las que interactúa simultáneamente cada par de actores del entorno institucional y social. Esta matriz corresponde a los vínculos indirectos entre los actores del entorno institucional y social, mediados por sus vínculos directos con las organizaciones de la RHSB. En este escenario se establecen nuevas prominencias, sin embargo y por las mismas razones del caso anterior, las posibles tensiones entre actores del entorno no son discernibles en este análisis.

\subsubsection{La red del entorno institucional.}

La matriz donde se representa el vínculo indirecto entre actores del entorno institucional y social se construye tomando el total de las organizaciones de la RHSB con que interactúan explícita y simultáneamente un par de actores del entorno. Esta matriz también es simétrica. 


\subsubsection{Análisis de centralidad}

En este caso no es posible calcular la centralidad de cercanía debido a que la matriz no es conexa. Se puede sin embargo analizar la centralidad de intermediación, Tabla 7. La matriz de vínculos indirectos entre actores del entorno institucional y social se dicotomizó tomando un umbral de 1.05, correspondiente al promedio de las entradas fuera de la diagonal de la matriz.

\begin{tabular}{|l|c|c|}
\hline & Grado & Intermediación \\
\hline La Red de Humedales & 77 & 7.450 \\
\hline Colegios Vecinos & 71 & 7.450 \\
\hline EAAB & 61 & 4.600 \\
\hline JACs & 61 & 2.333 \\
\hline DAMA & 60 & 2.333 \\
\hline ABO & 51 & 1.600 \\
\hline Min. Ambiente & 50 & 3.450 \\
\hline Comunidad Perimetral & 48 & 0 \\
\hline Alcaldías Locales & 48 & 2.333 \\
\hline CAR & 47 & 3.450 \\
\hline Universidades & 44 & 0 \\
\hline Organismos de & 39 & 0 \\
\hline Jardín Botánico & 34 & 0 \\
\hline
\end{tabular}

Tabla 7: Índices de centralidad de grado e intermediación de Freeman para los actores más prominentes del entorno institucional y social.

\subsubsection{Agrupación por cohesión}

En este caso se encuentran cuatro cliqués que, de una parte, nos indican prominencias $y$, de la otra, nos muestran subgrupos relevantes. Dentro de los cliqués el segundo se relaciona principalmente con el entorno local.

1: La Red de Humedales, Colegios Vecinos, EAAB, Min. Ambiente, CAR, DAMA, JACs, Comunidad Perimetral, Alcaldías Locales, ABO, Universidades, Jardín Botánico, Organismos de Control del Estado 2: La Red de Humedales, Colegios Vecinos, EAAB, DAMA, JACs, Alcaldías Locales, Policía Grupos, ecológicos locales 3: La Red de Humedales, Colegios Vecinos, EAAB ,Min. Ambiente, CAR, Alcaldía Mayor 
4: La Red de Humedales, Colegios Vecinos, Min. Ambiente, CAR, Urbanizadores Locales, ABO

Esta información destaca la prominencia de la RHSB, los colegios vecinos, el Ministerio del Medio Ambiente, la Empresa de Acueducto de Bogotá (EAAB), la autoridad ambiental regional (CAR), el Departamento Administrativo del Medio Ambiente del Bogotá (DAMA), las Juntas de Acción Comunal (JACs), las Alcaldías Locales y la Asociación Bogotana de Ornitología (ABO). Figura 5.

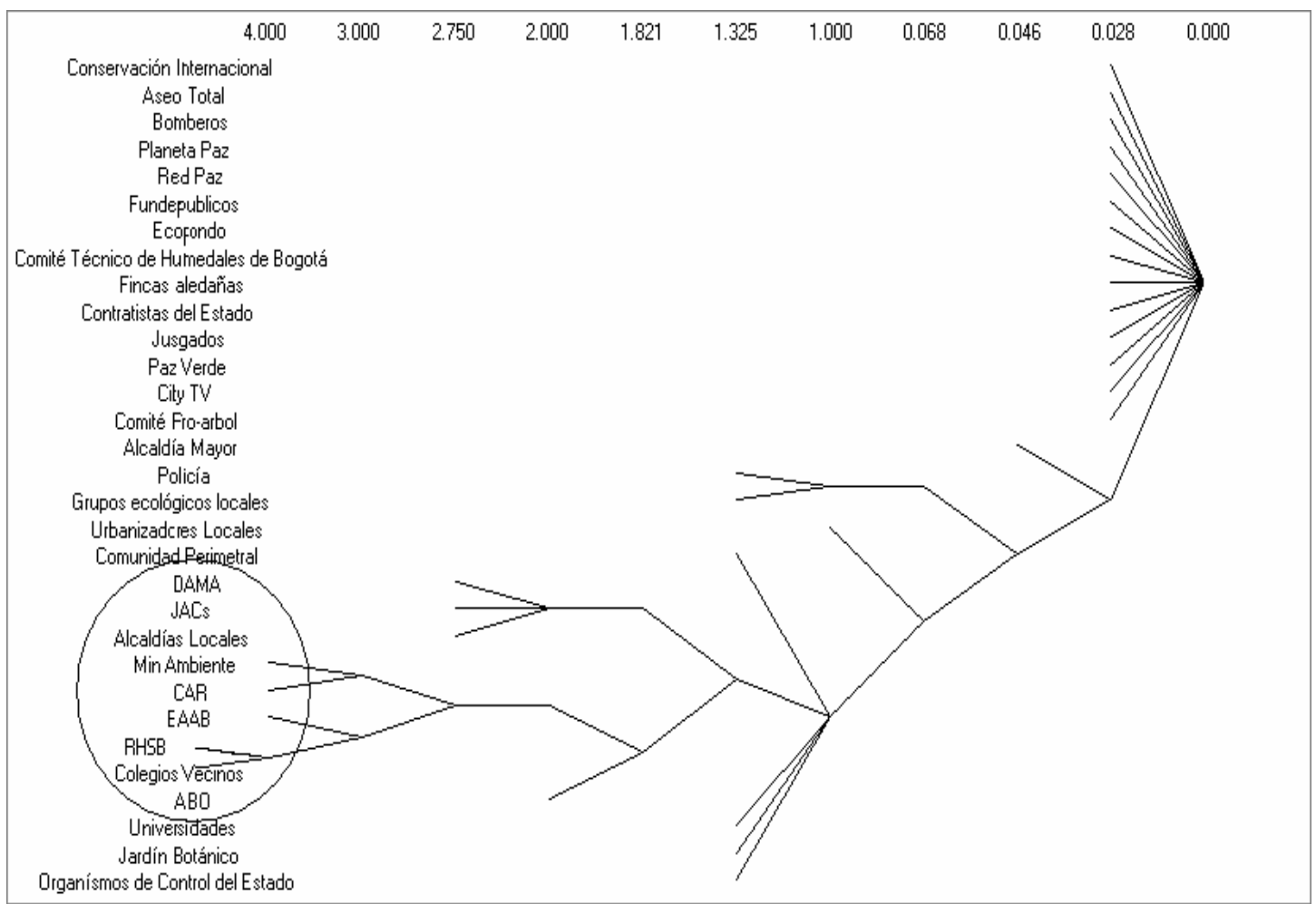

Figura 5: Presentación en la forma de árbol de los cliqués del entorno institucional y social según sus vínculos indirectos. (Draw, Borgatti, 2002)

Con base en las prominencias encontradas en estas agrupaciones se hizo la selección de los actores para efectuar un análisis cualitativo de sus vínculos e identificar algunas de las tensiones que existen en la red. 


\section{Discursos, significados y prácticas de la gestión ambiental en los humedales de Bogotá.}

Esta sección reconstruye, con fragmentos de los discursos ${ }^{11}$ de los actores, la historia que conjuga la interacción entre dos tipos de actores que se han constituido en nodos de paso obligado en la gestión ambiental de los humedales de Bogotá: El primer tipo de actor es la ciudadanía organizada en la RHSB. El segundo tipo de actor son las instituciones del estado locales, regionales y nacionales con competencia en la gestión ambiental de los humedales de Bogotá, tales como el Departamento Técnico Administrativo del Medio Ambiente DAMA-, la Empresa de Acueducto y Alcantarillado de Bogotá -EAAB- y el Ministerio del Medio Ambiente. Estas historias se organizan en los movimientos esenciales de la sociología de la traducción por parte de los actores nombrados arriba: problematización, Interesar, enrolamiento y movilización, evidenciando las tensiones actuales del proceso de gestión ambiental de los humedales de Bogotá.

El centro de la historia trata sobre la controversia sobre la definición del uso de los humedales, dilema que consiste en la conservación de sus valores ecológicos o su destinación a ser espacio público para la recreación. Para el primer tipo de uso las acciones deben estar encaminadas a restaurar y conservar los humedales como AP. Para el segundo tipo de uso los humedales deben ser recuperados como parques y zonas verdes de la ciudad.

\subsection{Los humedales de Bogotá ¿parques recreativos o ecosistemas estratégicos?}

\subsubsection{La problematización: convertirse en el punto de paso obligado}

La RHSB, como vimos en la sección anterior, es prominente en la red de gestión ambiental de los humedales de Bogotá. El liderazgo de esta organización ciudadana se inició con un grupo de vecinos con la iniciativa de actuar en favor de la conservación de los humedales de Suba, principalmente los de la Conejera y Córdoba, hace aproximadamente diez años.

\footnotetext{
11 Los fragmentos de los discursos de los actores de estas historias se retoman de fuentes primarias mediante entrevistas semi-estructuradas y observación directa en debates públicos: sobre el POT de Bogotá , sobre la Sabana de Occidente, Universidad Nacional y Sanciones sobre acción Popular Humedal Córdoba, Ministerios del Medio Ambiente, y revisión de archivos institucionales. Las fuentes secundarias son discursos extractados de documentos técnicos e informes de gestión elaborados por los actores en cuestión.
} 
Mas de 250 personas han presenciado las reuniones de conformación de la RHSB entre 1999 y el 2000 (Archivo Fundación Humedal la Conejera, 1999, 2000). Esta emergencia social tiene sus raíces en las acciones de varias organizaciones ciudadanas en torno a los humedales, con base en los retos de la gestión ambiental propuestos en la nueva ley de Ordenamiento Territorial (Ley 388/1997) y el compromiso adquirido por el Estado colombiano al ratificar la convención Ramsar (Ley 357 de 1997). La RHSB es ahora un punto de paso obligado para cualquier acción ambiental en los humedales de Bogotá, tanto para ciudadanos como ONGs y entidades del Estado que consultan con las organizaciones de la RHSB para sus decisiones y acciones sobre los humedales de Bogotá.

\section{Las organizaciones que constituyen la base de la Red de Humedales de la Sabana de Bogotá son:}

Fundación Humedal la Conejera, Fundación Humedal el Tintal, Fundación La Tingua, Junta de Acción Comunal de Niza, Corpotibabuyes, Econiza, Mesa Ambiental Bosa, Corporación Iraca, Asociación para el Desarrollo Social y Ambiental ADESSA, Fundación Amigos del Planeta, CORDEINSA, CORGUALI, Fundación Humedal Torca-Guaymaral, Junta Comunal Tabora.

Han presenciado las reuniones de la red y se han articulado a sus objetivos y causas actores como:

PRAES (Proyectos ambientales escolares), alumnos y padres de familia de los colegios, EAAB, Deeb Asociados, Casa Tierra, ICMAR, Corparque, Edificio León, Urbanización Camino Verde, Crisálida, Cabildo Verde Soacha, Comité Niza, Comité Edificio Simón Bolívar, Edificio Talavera, Alcaldía Funza, Rotarac, CAR, Fundepúblico, Casa Tierra, Entorno, DAMA, Vigilancia y Seguridad, Edificio Valdepeñas, Edificio Aranda, Veeduría Ambiental Engativá, El Espectador, Asociación Bogotana de Ornitología, Proagua, Iglesia del Nazareno, Comité Ecológico San José de la Granja, JAC Niza, Ecofondo, Gedescom, Fundación al Verde Vivo, Acueducto Mosquera, Universidad Nacional, Universidad Distrital, Universidad de los Andes, Universidad Javeriana, Universidad La Sabana, Universidad de Santo Tomás, Universidad Jorge Tadeo Lozano, Universidad Externado de Colombia.

Tabla 8: Listado de actores que han participado de la configuración de la Red de Humedales de la Sabana de Bogotá (1999-2000). Fuente: Archivo Fundación Humedal La Conejera (2002).

De otro lado, el DAMA y la EAAB, como entidades locales con competencias sobre el asunto del manejo de los humedales de Bogotá, son actores centrales de la red de gestión ambiental de los humedales de la ciudad. Éstas tienen el mandato de desarrollar acciones de conservación sobre los humedales, emanado de las leyes y las normas al igual que de las políticas nacionales, normativa que proviene de la sanción del Código de Recursos Naturales en 1974, el acuerdo 7 de 
1979 para acotar los cuerpos de agua mediante el cual se le asignan las tareas de acotamiento y amojonamiento de las rondas a la EAAB, y el amplio desarrollo normativo sobre la conservación de los humedales durante la última década (Ley 99 de 1993, Ley 165 de 1994; Acuerdo 19 de 1994: Fallo No 642 del Consejo de Estado; La Ley 357 de 1997 entre otras)

La RHSB ha ido elaborando sus propias traducciones del paisaje de los humedales, defendiéndolos en sus prácticas de gestión como espacios públicos y ecosistemas con valores ecológicos de importancia para la conservación y de importancia ambiental para la ciudad. Esta traducción se observa en el texto de su misión:

"convertir los humedales de la sabana de Bogotá en relictos y santuarios de flora y fauna del Distrito Capital y del mundo, protegiendo estos sistemas para que las comunidades que los rodean gocen de un ambiente sano. Es así como la prioridad es preservar este ecosistema contra cualquier política o acción que vaya en contra de su conservación y atente contra el carácter natural del ecosistema. Igualmente se plantea contribuir a la concientización de las comunidades acerca de los valores que tienen los humedales y lograr su respeto y apreciación por parte de otros actores" (Archivo, FHC).

La EAAB presenta la visión que tiene sobre los humedales así:

\begin{abstract}
"Humedales restaurados y rehabilitados ecológicamente, cumpliendo con sus funciones ecosistémicas esenciales, como son el mantenimiento de la vida silvestre, la regulación hidráulica, la retención de sedimentos y la depuración de las aguas; integrados a la ciudad como ecosistemas urbanos estratégicos que, adicionalmente, posibiliten la educación ambiental, la investigación y la recreación pasiva de los ciudadanos". (EAAB y CI; 1999b: 35).
\end{abstract}

Y el DAMA en su informe de gestión del periodo 1998-2000 también presenta una visión donde se puede leer cuál es el significado de los humedales para ésta:

\footnotetext{
"Desde un punto de vista ecosistémico, uno de los componentes más importantes del Sistema Hídrico lo constituyen los Humedales localizados en el interior de la ciudad o en sus zonas rurales adyacentes. Son definidos como aquellas tierras permanentemente húmedas o inúndales durante parte o todo el año y cuya lámina de agua no alcanza por lo general más de seis metros de profundidad." (2000a: 1).
}

Los humedales son incluidos dentro de la categoría de ecosistemas estratégicos al igual que de áreas verdes definiéndolas así:

"entre los ecosistemas estratégicos que están dentro del perímetro urbano se destacan: EI Sistema Hídrico, conformado por los cuerpos de agua (humedales, ríos, canales, lagos). EI Sistema de áreas Verdes Urbanas, conformado por aquellas áreas que además de cumplir una función ecológica y ambiental, cumplen una función social y de ornato y por lo tanto constituyen zonas de protección, como son las Zonas Verdes urbanas y Rondas de los ríos y humedales y los 
Cerros que enmarcan la ciudad por el norte, oriente, sur y suroccidente". (DAMA, 2000a: 1)

Igualmente, en "Proyecto de manejo y conservación de ecosistemas Urbanos" el DAMA muestra su doble intención con los humedales, la de conservación y la de uso recreativo de estos ecosistemas:

\begin{abstract}
Mediante el "Proyecto de manejo y conservación de ecosistemas urbanos" el DAMA busca "Proteger, conservar, restaurar, ampliar y mejorar el potencial paisajístico, ecológico y recreativo ofrecido por el sistema orográfico, zonas verdes y humedales de la ciudad para el disfrute de la población y para garantizar que estas áreas perduren" (DAMA, 2000a:1).
\end{abstract}

En estas definiciones aparecen dos puntos que hacen parte central de la controversia sobre la gestión ambiental de los humedales de Bogotá: la noción de ecosistema estratégico y la noción de recreación. En la práctica de la gestión ambiental de cada actor las visiones sobre los humedales se acentúan, observándose puntos de encuentro y diferencias marcadas como veremos en el segundo momento de la traducción: el interesarse.

Las prácticas sociales de los ciudadanos vecinos de los humedales, orientadas a su recuperación y protección, emergen al iniciar la década de 1990. Éstas se van articulando entre si y constituyen una trama de vínculos que busca recuperarlos y conservarlos. Los integrantes de la RHSB sostienen que en la época en que surgió este interés por recuperar y conservar los humedales, los gobiernos locales y las entidades del Estado aún no se preocupaban por su conservación. Las instituciones del Estado mantenían las viejas prácticas que definían los humedales más como un obstáculo que como una parte importante del ordenamiento del territorio. Por ejemplo, la CAR tenía un programa para secar los pantanos, el HIMAT tenía el programa de adecuación de tierras que consistía en drenar y secar pantanos, y el INCORA otorgaba tierras en zonas pantanosas promoviendo su 'adecuación'.

\title{
3.1.2 Interesar: convencer a los posibles aliados
}

La palabra interés, etimológicamente compuesta por dos raíces latinas: Inter $=$ entre y es $=$ eje, nos habla sobre estar 'entre'. Pero ¿entre quienes? Entre los actores sociales y los elementos o los asuntos por los que los primeros quieren interpelar, en este caso los humedales de Bogotá. Es así como los vecinos del humedal la Conejera se definieron a sí mismos como gente interesada en proteger los humedales de los actores que estaban destruyéndolos, convirtiéndose en el punto de paso obligado para hacer cumplir las leyes que el Estado colombiano había formulado para proteger dichos lugares.

EI DAMA y la EAAB también han establecido sus vínculos con la comunidad científica y con las demás comunidades para validar su gestión y tener legitimidad local en la misma, sobre todo cuando la misma ciudadanía se ha organizado para recuperar estos ecosistemas. Sin embargo, las competencias de estas entidades y los mandatos que 
tienen que cumplir son mucho más amplios que su interés por la conservación de los humedales. En el plano de las prioridades, los humedales tienen una importancia relativa menor para estas entidades que para la RHSB, cuya misión-visión está íntimamente relacionada con estos lugares.

\subsubsection{Enrolamiento: definiendo los roles que los aliados pueden cumplir}

En el proceso de organización de la acción ciudadana frente a la recuperación y conservación de los humedales ésta busca el apoyo de la EAAB, el DAMA, la CAR y las empresas públicas de limpieza, y vincula a sus actividades de protección y control policías bachilleres, jueces y magistrados de la Defensoría del Pueblo, establece convenios con universidades para ejecutar proyectos de tesis, involucra a los maestros, a los alumnos y a los padres de familia de los colegios vecinos. Simultáneamente hacen parte de su acción la protección de todas las especies de animales que habitan los humedales, la siembra de árboles asignándoles su respectivo padre o madre adoptiva, y mantienen la vegetación nativa y el hábitat de aves migratorias que encuentran en este lugar sitio para su descanso y alimentación durante el viaje. Todos ellos se convierten en actores importantes de los humedales y su paisaje. Todas las acciones se convirtieron en un acto pedagógico.

Los resultados de la Fundación Humedal la Conejera -FHC -, como actor exitoso en la gestión ambiental de los humedales de la ciudad, llamaron la atención de otros grupos organizados de la ciudad quienes fueron a conocer esta experiencia y a buscar apoyo para replicarla en otros casos similares. Así, en Córdoba, Santa María del Lago, los humedales del Tintal, Torca-Guaymaral y Tibanica, se empezaron a fortalecer otros grupos ciudadanos que tenían el mismo interés y se inició el intercambio que dio lugar a la constitución de la RHSB.

Ahora existen 13 nodos activos de la RHSB (10 en la ciudad de Bogotá, y 3 en municipios vecinos) quienes en coordinación con colegios, vecinos, grupos de investigadores de distintas disciplinas (biología, ingeniería ambiental, sociología, trabajo social, entre otros) y procedencias (la Asociación Bogotana de Ornitología, el Instituto de Ciencias Naturales de la Universidad Nacional, y posteriormente del Instituto de Investigación de Recursos Biológicos Alexander Von Humboldt, el Ministerio de Medio Ambiente y la Unión Internacional para la Conservación de la Naturaleza -UICN-), han logrado establecer criterios de manejo y acciones de conservación y educación ambiental en los humedales; así mismo han vinculado entidades que, al igual que las personas de la FHC, estaban buscando la conservación de estos ecosistemas.

Sin embargo estas alianzas no han sido estables. En 1994, cuando el DAMA aún se estaba estructurando, hubo una gran empatía con la FHC, mutuamente aliadas en la defensa de las AP de la ciudad, sin embargo al final de la primera administración de el alcalde Mockus 
(1994-96) y durante la gestión del alcalde Peñalosa (1997- 1999), hubo diferencia de criterios frente a los humedales entre estas dos organizaciones, pues los humedales empezaron a ser vistos como zonas potenciales para la construcción de parques y zonas verdes para la recreación de los habitantes de la ciudad. Esta nueva visión no conjugaba con el criterio que la FHC venía trabajando.

De otro lado, el DAMA ha establecido estrategias de participación ciudadana integrando a la comunidad mediante labores como la revegetalización y los procesos educativos. Así está concebido en el Protocolo diseñado para la recuperación de los humedales:

"Al encontrarse los humedales insertados en un espacio urbanizado, su gestión conservacionista deberá atender el entorno social, conciliando la función de preservación con la incorporación en el espacio urbano. La permanencia del Área Natural Protegida, depende del apoyo de la comunidad, principalmente la del área de influencia inmediata al igual que reduce los costos de plantación, crea sentido de pertenencia en la comunidad garantiza el éxito y la permanencia y se constituye el mejor escenario para facilitar y garantizar el desarrollo de futuras acciones de manejo de los humedales" (EAAB, CI, 1999c: 22).

\subsubsection{Movilización: Logros y alcances del proceso de traducción}

La traducción que hace la RHSB sobre los humedales enfatiza en sus características ecológicas, por lo cual sus prácticas de gestión ambiental buscan su restauración para que continúen cumpliendo con su función de hábitat ecológico. Esta visión los ha llevado a darles cabida a los humedales en el desarrollo de la ciudad, incluyéndolos como parte de su paisaje en lugar de desaparecerlos como sucede con las prácticas indiscriminadas de urbanización sobre el territorio. La RHSB atribuye el éxito de esta traducción principalmente a tres aspectos:

- La conciliación: como primera etapa de negociación con los actores que están perjudicando los humedales.

- El seguimiento exhaustivo a los procesos judiciales iniciados para que lleguen a la fase de sentencia.

- Las acciones con resultados: éstos motivan la solidaridad ciudadana y demuestran que sí se puede (por ejemplo: jornadas de limpieza, reforestación, cercamiento, limpieza del espejo de agua, etc.). La perseverancia, la continuidad y la creatividad de la RHSB para solucionar los problemas y sobrepasar los obstáculos también son aspectos centrales para el logro de sus objetivos.

- La vía judicial: interposición de acciones judiciales y administrativas, de derechos de petición, acciones de tutela y acciones populares entre otras.

Entre los logros centrales de la RHSB están la consolidación de procesos judiciales (fallos de las cortes) y promoción de legislación, como el Acuerdo 6 de 1990, el acuerdo 19 del 1994 y el acuerdo 27 de 1995, que ha consolidado los humedales de Bogotá como Áreas 
Protegidas y Reservas Naturales. La traducción que la ciudadanía organizada en la RHSB ha hecho sobre los humedales, articulada a la misma definición que de estos sitios hace la convención RAMSAR y las leyes nacionales que promulgan su conservación como ecosistemas estratégicos, ha logrado el posicionamiento del tema en la agenda de la ciudad en varios ámbitos. De igual forma la presencia de la RHSB ha dado fuerza a las autoridades ambientales locales como el DAMA y nacionales como el Ministerio del Medio Ambiente, quienes han encontrado en ellos un aliado en su mirada y sus objetivos.

Entre los principales obstáculos que ha tenido que sortear la RHSB están los planes y proyectos de las entidades del Estado que traducen estos sitios bajo otros criterios, como por ejemplo el uso de los humedales como zonas verdes y parques para la recreación, y las dificultad que estas entidades han mostrado para cumplir con las actividades de amojonamiento, vigilancia y control de las rondas sobre actividades privadas que siguen actuando sobre estos sitios con otros enfoques y criterios, principalmente de beneficio económicos.

EI DAMA y la EAAB también han invertido un gran esfuerzo institucional sobre los humedales. Por ejemplo, han realizado contratos con diversas firmas para establecer el estado actual de los humedales (EAAB y CI, 1999c; DAMA, 2000b) y para elaborar los planes maestros que definen los diseños paisajísticos y los protocolos de recuperación y conservación, tales como el de Córdoba y Juan Amarillo, la Conejera, Santa María del Lago entre otros (DAMA, 2000b; Unión Temporal Diego Cabal y Asociados, sin fecha). Sin embargo, aun no existe claridad frente al tipo de manejo que se le dará a los humedales pues en los contratos prevalecen aspectos que les da una integración más urbana que ecológica. Particularmente se destacan las obras de infraestructura física que buscan establecer parques 'ecológicos' como alamedas, ciclorutas, senderos peatonales, puentes, alumbrado público, sustracción de la vegetación del pantano. Estas obras ya se ejecutaron en el humedal de Santa María del Lago y están en proceso de ejecución en el humedal de Córdoba.

Según el DAMA uno de los principales problemas encontrados en la ejecución de proyectos de este tipo fue la falta de claridad, perspectiva y entendimiento por parte de diversas autoridades ambientales del nivel nacional y regional, sobre el concepto de recreación pasiva asociado a la posibilidad de disfrute y uso sostenible de los ecosistemas urbanos (DAMA, 2000a). Dicha situación se observa en el caso de Córdoba, donde se planea construir un parque lineal que atraviese la ciudad de oriente a occidente. La obra nace en los cerros orientales, avanza por la quebrada Los Molinos y la calle 106, llega al humedal de Córdoba se conecta con el humedal Juan Amarillo y finaliza en el parque La Florida. El proyecto pretende invertir 10.000 millones de pesos en los que las ciclorutas y plazoletas marcan un rasgo central de esta propuesta.

Con respecto a estos proyectos la RHSB argumenta que a pesar de que en el papel los planes de manejo de los humedales parecen acordes 
con la política y los lineamientos sobre las bases técnicas para la conservación de los humedales interiores, en los contratos de ejecución se observan otros criterios pues integran, por ejemplo, dragados masivos que arrasan con la vegetación nativa de la ronda (Castaño, 2002) o plantean obras civiles tales como plazoletas y ciclorrutas, aspectos de la llamada recuperación "que comprometen la conservación o las posibilidades de recuperación de algunos de sus valores más importantes como el de su biodiversidad" (Fundación Humedales, 2001). Igualmente, Castaño (2002) sostiene que el carácter de AP que tienen los humedales, y el hecho de pertenecer a la Estructura Ecológica Principal del Distrito, deberían ser suficientes razones para evitar convertirlos en parques urbanos y que se continúe utilizándolos como parte del sistema de alcantarillado de la ciudad.

\subsection{Ambivalencias de la traducción y las tensiones en la red}

En los cuatro momentos de la traducción observamos, a manera de síntesis, que los actores traducen el mandato de la ley y la normatividad con interpretaciones que, si bien tienen algunos puntos de encuentro, son fundamentalmente diferentes. De un lado, las autoridades ambientales no tienen una posición unificada frente al tema de los humedales en la ciudad. El quehacer del DAMA y la EAAB integran acciones que transforman el paisaje de los humedales en el marco de la recreación y la ornamentación e infraestructura urbana. El Ministerio del Medio Ambiente busca armonizar esta visión con las disposiciones legales y la RHBS busca hacer de estos sitios AP en el marco de la conservación de ecosistemas estratégicos

Este análisis complementa los resultados realizados en el marco del ARS en varios aspectos. De una parte permite evidenciar un actor del entorno institucional que, teniendo un alto grado de centralidad dentro del ARS, debido a su misión y las acciones que emprende, cobra una posición de mayor centralidad. De otra parte, permite evidenciar una dinámica compleja de las tensiones en la red, proveniente de ambivalencias en la traducción del marco legal y del conocimiento sobre el lugar.

\section{Conclusión}

Las interacciones socioambientales moldean el paisaje de un lugar y por lo tanto la propuesta de entenderlas mediante la noción del LugarRed plantea interesantes retos de investigación debido a la multiplicidad de dimensiones sociales y ambientales que integra. Las herramientas que abordan el conocimiento del Lugar-Red son instrumentos importantes de gestión al contribuir a la identificación sistemática de los vínculos de los actores sociales con el espacio y el ambiente en un marco temporal determinado. La identificación de actores prominentes y los patrones relacionales en la red, por ejemplo, facilitan a su vez la identificación de actores que pueden ser cruciales para difundir una visión del territorio o colaborar al logro de un 
determinado objetivo, así como a construir alianzas o promover vínculos.

De otro lado, las narrativas del Actor-Red descomponen las acciones de los actores para conocer cómo estos problematizan, interesan, involucran y movilizan a distintos actores para lograr sus objetivos. Esta manera de registrar la acción social devela de forma precisa los elementos ambivalentes que están presentes en los vínculos entre los actores, es decir que permite conocer lo que fluye por la red, marcando sectores de poder o de tensión o acuerdo. Es así que en esta aplicación el ARS provee una representación de la estructura de los patrones relacionales entre los actores y entre estos y su entorno, mientras que la sociología de la traducción permite evidenciar los aspectos de la ambivalencia en los vínculos. El ARS facilitó observar el conjunto de actores en sus patrones de relación mostrando prominencias en la red al igual que aspectos de cohesión del conjunto de actores analizado. Adicionalmente, esta observación nos muestra un entorno institucional que también determina de forma indirecta las capacidades y habilidades del grupo para alcanzar sus objetivos mediante alianzas o disputas. La información relacional que obtenemos sobre ese entorno, aproximándonos únicamente a 8 actores y haciendo dos preguntas muy sencillas, demuestra el poder de estas herramientas. Finalmente, teniendo en cuenta que las relaciones sociales no tienen un significado unívoco al establecer los vínculos, y menos en aspectos que conllevan un cúmulo de significado tan complejo como lo son las acciones de gestión ambiental en AP, las narrativas del Actor-Red son un elemento metodológico complementario de métodos cuantitativos como el ARS para analizar estos vínculos.

Incorporar en un solo análisis los actores y sus vínculos, entre sí y con el entorno, identificando aspectos sobre el poder y sus efectos sobre el ambiente, es de gran importancia para establecer estilos de gestión que tiendan más hacia modos de ensamblaje colectivo que a propuestas que contribuyen a la exclusión de distintos puntos de vista de los actores sociales e institucionales sobre el territorio. El diálogo y el debate entre estas visiones es posible siempre y cuando éstas se hagan visibles, y la propuesta aquí presentada las visibiliza de forma rigurosa. Generalmente los espacios de debate no permiten mostrar quién es quién en el escenario, y muchas voces se ahogan en los espacios oficiales o en los debates públicos. Es así que esta propuesta puede servir como facilitadora del manejo de procesos de participación con el fin de darles cabida a todos los actores que pueden hacer parte de los debates sobre los procesos de gestión tal como es el caso de los humedales de Bogotá.

\section{Agradecimientos}

Los autores agradecen a COLCIENCIAS por la financiación del proyecto de investigación 1205-13-11102. Así mismo D. Palacio y R. Hurtado por financiación de sus estudios de doctorado y L. Garavito por 
financiación del programa Jóvenes Investigadores. R. Hurtado se encuentra actualmente en comisión de servicios en COLCIENCIAS. 


\section{Bibliografía}

ANSELL, CH. (2003) Community Embeddedness and Collaborative Governance in the San Francisco Bay Area Environmental Movement. En Social Movements and Networks. Relational Approaches to Collective Action. Edited by Mario Diani y Doug McAdam. New York. Oxford University Press. Págs: 123-144

BOCZKOWSKI, P. J. (1997) "Ciencias sin cajas negras y política sin experimentos repetibles: conversando con Bruno Latour sobre ciencia y política en los tiempos de la vaca loca" en Redes, revista de estudios sociales de la ciencia No. 9 Vol. 4 Buenos Aires. Págs: 141-152.

BORGATTI, S.P. (2003) Conceptos Básicos de Redes Sociales. www.analytictech.com/networks

BORGATTI, S.P., EVERETT, M.G. AND FREEMAN, L.C. 2002. Ucinet for Windows: Software for Social Network Analysis. Harvard: Analytic Technologies.

CALLON, M. (1986) Some Elements of Sociology of Translation. Domestication of the scallops and the fishermen of St. Brieuc Bay. In Power, Action and Belief: a new Sociology of Knowledge? Ed. by John Low. London. Routledge \& Kegan Poul. Pp 197-233.

CASTAÑO, M. (2002) Verdades sobre el Humedal de Córdoba. Entre Juncos Boletín de la Red de Humedales de la Sabana de Bogotá. No. 5. pp 3

CLEGG, S. (1989) Frameworks of Power. London. SAGE Publications.

DEPARTAMENTO TÉCNICO ADMINISTRATIVO - DAMA - (2001) Santa María del Lago, primer humedal recuperado como aula ambiental para Bogotá. Los Humedales en la gestión ambiental y el ordenamiento del DC. www.dama.gov.co/comunicados de prensa. 1 pp

www.dama.gov.co 19pp.

(2000a) Informe de Gestión 1998-2000.

(2000b) Ejecución parcial del Plan Maestro para la Recuperación del Humedal Santa María del Lago en Bogotá. Interventoría de la recuperación y de la construcción de obras civiles. Informe mensual de Interventoría No. 2 Mes de agosto de 2000. Bogotá. Consorcio Proeza Ltda. Cenerco Ltda. 35 pp.

DIANI, M (2003) Introducción. En Social Movements and Networks. Relational Approaches to Collective Action. Edited by Mario Diani y Doug McAdam. New York. Oxford University Press. Págs: 1-18

DIANI, M. (1995) Green Networks. A structural Analysis of the Italian Environmental Movements. Edinburgh. Edinburgh University Press. 
DIANI, M. (1992) Analysing Social Movement Networks. En Studing Collective Action. Ed. by Mario Diani and Ron Eyerman. London. SAGE Publications. SAGE Modern Politics Series Volume 30. PP 107-135

EMPRESA DE ACUEDUCTO Y ALCANTARILLADO DE BOGOTÁ, EAAB y CONSERVACIÓN INTERNACIONAL COLOMBIA -CI (1999a) Síntesis del estado actual de los humedales bogotanos. Recuperación de los humedales de la Sabana de Bogotá. Alternativas hacia una viabilidad ecológica y social. Bogotá. EAAB y CI. 200 pp Humedales de la Sabana de Bogotá. Alternativa hacia su viabilidad ecológica y social. Bogotá. EAAB, Conservación Internacional Colombia. 250 pp.

(1999c) Protocolo general para el desarrollo de actividades de revegetalización en los humedales bogotanos. Recuperación de los humedales de la Sabana de Bogotá. Alternativa hacia su viabilidad ecológica y social .Bogotá. EAAB, Conservación Internacional Colombia. 114pp.

ENTRE JUNCOS (2000) Los humedales de Santa Fe de Bogotá: una propuesta de categorización y uso desde la sociedad civil. Entre Juncos Año 1 No. 2. pp. 2-3.

FAUST, K. (2002) "Las Redes Sociales en las Ciencias Sociales y del Comportamiento" en Análisis de Redes Aplicaciones en Ciencias Sociales. Editado por Jorge Gil Mendieta y Samuel Schmidt. Ciudad de México. Instituto de Investigaciones en Matemáticas Aplicadas y En Sistemas Universidad Nacional Autónoma de México. Págs.: 1-12

FREEMAN, L.C (2002) "Detectando grupos sociales en datos cuantitativos" en Análisis de Redes Aplicaciones en Ciencias Sociales. Editado por Jorge Gil Mendieta y Samuel Schmidt. Ciudad de México. Instituto de Investigaciones en Matemáticas Aplicadas y En Sistemas Universidad Nacional Autónoma de México. Págs. : 23-37

FREEMAN L C (1979). 'Centrality in Social Networks: Conceptual clarification', Social Networks 1, 215-239

GHIMIRE, K. B. and PIMBERT, M. P. (1997) Social Change and Conservation: an Overview of Issues and Concepts. In Social Change and Conservation. Edited by Krishna B. Ghimire and Michel P. Pimbert. London. Earthscan. pp 1-45

HANNEMAN, R.A (2001) Introduccion a los Metodos Del Analisis de Redes Sociales. Capitulo Sexto: Centralidad y Poder. Departamento de Sociología de la Universidad de California.

http://wizard.ucr.edu/ rhannema/networks/text/textindex.html 
IACOBUCCI, D. (1994) Graphs and Matrices. In Social Network Analysis, Methods and Applications. Structural Analysis in the social sciences No. 8. Ed. by Stanley Wasserman and Katherine Faust. Cambridge. Cambridge University Press. Pp 92-165

INGOLD, T. (1992) Culture and perception of the environment. In Bush Base: Forest Farm. Culture, Environment and Development. Ed. by Elisabeth Croll and David Parkin. London. Routledge. Pp 39-55

LATOUR, B. (1999) On recalling ANT. In Actor-Network Theory and After. Ed. by John Law and John Hassard. Oxford. Blackwell. Pp 15-25

LAW, J. (1999) 'Notes on the Theory of the Actor-Network: ordering, Strategy and Heterogeneity'. In Actor-Network Theory and After a Day Seminar reading home page Centre for Science Studies, Lancaster University.

http://www-comp.lancs.uk/sociology/ANT\&after1reading1.html.

LEE, N. and STENNER P. (1999) Who pays? Can we pay them back?. In Actor Network Theory and After. Ed by John Law and John Hassard. Oxford. Blackwell. Pp 90-112

McNEELY, J. A.(1994) Protected areas for the 21st century: working to provide benefits to society. Biodiversity and Conservation 3, 390-404.

PALACIO T, D.C (2002) El parquet nacional Utria, un Lugar-Red. Una propuesta de análisis socioambiental para la gestión de Áreas Protegidas. En Territorios. Revista de Estudios Regionales y Urbanos. No. 8.

PALACIO T, D.C (2001) Place-Networks: A Social - Environmental Approach for the Conservation of Protected Areas. The Case Studies of Monte Tezio (Italy) and Utria (Colombia). Thesis to obtain Ph. D degree in Development Studies. Centre for Development Studies. University of Wales, Swansea.

TURNER, J. (1988) A Theory of Social Interaction. Stanford, California. Stanford University Press..

WASSERMAN, S. y FAUST, K. (1994) Social Network Analysis. Methods and Application. Structural Analysis in the social sciences No. 8 . Cambridge. Cambridge University press.

WEST, P.C. y BRECHIN, S. R. (1991) National Parks, Protected Areas, and Resident Peoples: A Comparative Assessment and Integration. In Resident Peoples and National Parks. Social Dilemmas and Strategies in International Conservation. Ed. by Patrick C. West and Steven R. Brechin. Tucson. The University of Arizona Press. Pp 363-400 